\title{
The effect of dexamethasone on labor induction: a systematic review
}

\author{
Zaynab Mohaghegh ${ }^{1}$, Shahla Faal Siahka $2^{2^{*}}$ (D) Hadis Bahmaei ${ }^{3}$, Foruzan Sharifipour ${ }^{4}$, Ehsan Kazemnejad Leyli ${ }^{5}$ and \\ Maryam Zahedian ${ }^{6}$
}

\begin{abstract}
Background: To evaluate the effect of dexamethasone administration on the interval between initiation of labor induction and active phase of labor.

Methods: The databases including PubMed, Cochrane Library, Embase, Scopus and Web of Science were searched for studies published up to June 27, 2021. Two types of articles were included: a) full-text articles published in English or any other languages, and b) Randomized Controlled Trials (RCTs). Participants were primi- or multigravida women with term or post-term pregnancy. The intervention group received parenteral or extra-amniotic dexamethasone whereas the control group received normal saline or no treatment before initiation of labor induction. All data were analyzed using Review Manager 5.3.

Results: Seventeen studies involving 1879 patients were included in the meta-analysis. Administration of dexamethasone reduced the interval between the initiation of labor induction and the beginning of active phase by about 70 min [MD: $-1.17(-1.37,-1.00) ; P<0.00001]$. Duration of the first stage of labor in the dexamethasone group was about 88 min shorter than that in the control. There were no maternal and fetal adverse effects.

Conclusions: Dexamethasone could significantly reduce the length of induction-active phase interval, and length of the first stage of labor, with no difference in maternal or fetal adverse effects.
\end{abstract}

Keywords: Dexamethasone, Labor induction, Corticosteroid, Cervical ripening

\section{Background}

Induction of labor refers to the process of stimulating contractions before the spontaneous onset of labor, either with or without ruptured membrane. Labor induction can be considered as a therapeutic intervention when the benefits of precipitous delivery to either the mother or the fetus are greater than the risks of pregnancy continuation [1]. Induction of labor is the most common obstetric procedure and the fastest-growing medical technique in the United States [2]. Most recently, the prevalence of induction has been estimated to

\footnotetext{
* Correspondence: faalshahla1@yahoo.com

2Department of Midwifery, Marand Branch, Islamic Azad University, Marand, Iran

Full list of author information is available at the end of the article
}

be $23.3 \%$ in the United States, $22.4 \%$ in Ethiopia, and 9\% in Sudan [3-5]. Rupture of the membranes without labor, gestational hypertension, oligohydramnios, nonreassuring fetal status, post-term pregnancy, and various maternal medical conditions such as chronic hypertension and diabetes are the common cause of start termination of pregnancy [6]. Several medical and non-medical methods are used for the induction of labor $[7,8]$. While oxytocin is the most conventional method, there are other effective methods including the use of prostaglandins such as misoprostol and dinoprostone as well as the application of some mechanical methods like stripping of membranes, artificial rupture of membranes, extraamniotic saline infusion, trans cervical balloons, and hygroscopic cervical dilators [9]. The success of

(c) The Author(s). 2021 Open Access This article is licensed under a Creative Commons Attribution 4.0 International License, which permits use, sharing, adaptation, distribution and reproduction in any medium or format, as long as you give appropriate credit to the original author(s) and the source, provide a link to the Creative Commons licence, and indicate if changes were made. The images or other third party material in this article are included in the article's Creative Commons licence, unless indicated otherwise in a credit line to the material. If material is not included in the article's Creative Commons licence and your intended use is not permitted by statutory regulation or exceeds the permitted use, you will need to obtain permission directly from the copyright holder. To view a copy of this licence, visit http://creativecommons.org/licenses/by/4.0/ The Creative Commons Public Domain Dedication waiver (http://creativecommons.org/publicdomain/zero/1.0/) applies to the data made available in this article, unless otherwise stated in a credit line to the data. 
induction and progression of labor depends on several factors including multiparity, low body mass index (BMI), ruptured membranes, tall height, low estimated fetal weight, and absence of comorbidities associated with placental insufficiency (e.g., preeclampsia) [10].

According to a study by Kawakita et al., of nulliparous women who underwent induction of labor in their study, $77.4 \%$ had a vaginal delivery [11]. The time required for the induction of labor, especially when there is an unfavorable cervix, increases the risk of cesarean delivery [10]. Some studies have reported the role of administering glucocorticoids such as dexamethasone in cervical ripening [12]. Although the role of glucocorticoids in the initiation of labor is still unknown, there is evidence supporting the role of glucocorticosteroid receptors in the fetal membranes at the beginning of the labor process $[13,14]$.

Corticotropin-releasing hormone $(\mathrm{CRH})$ in the female reproductive system is the main regulator of the hypothalamic-pituitary-adrenal axis [12, 15]. During pregnancy, the placenta and fetal membranes secrete large amounts of CRH. Also, CRH levels in plasma increase during labor, with the maximum value at vaginal delivery [16]. There is considerable evidence for the effect of dexamethasone on the duration of labor stages. The aim of the current systematic review was to examine the effect of dexamethasone on the length of the interval between the initiation of labor induction and the beginning of the active phase of labor. Moreover, the length of different stages of labor and maternal and neonatal outcomes were investigated.

\section{Methods}

Systematic Reviews and Meta-Analyses of Randomized Controlled Trials (RCTs) were used to conduct this systematic review [17].

\section{Search strategies}

The authors searched promulgated studies published until July 8. 2020 in databases and publishing services including Cochrane Library, Scopus, ISI Web of Science Core Collection, PubMed, and EMBASE. It is updated on June.27.2021.The keywords that were searched included "Corticosteroids", "Dexamethasone", "Deoxone", "Dexpak", "Induction of Labor", "Cervical Ripening". (Supplementary material).

\section{Inclusion and exclusion criteria}

Two types of articles were included in this review: a) full-text articles published in English or any other languages, and b) Randomized Controlled Trials (RCTs). Abstracts, comments, letters to editor, and observational studies were excluded.

\section{Participants}

The criteria for including the participants were as follows: an unfavorable cervix with a Bishop score of $\leq 4$; singleton pregnancy with a duration of at least 37 weeks according to a reliable date for the last menstrual period and a first trimester ultrasound evaluation; cephalic presentation and intact membrane; and normal amniotic fluid. Women with any of the following conditions were excluded from the study: uterine malfunction, macrosomia, placenta previa or placenta abruption risk, history of surgery on uterus, uterine contractions, fetal distress, and fetal occiput posterior position.

\section{Types of interventions}

The included studies involved intervention groups receiving dexamethasone before initiation of labor induction by any route of administration (intramuscular, intravenous or extra-amniotic) compared with control groups (placebo or no intervention).

\section{Types of outcome measures}

The primary outcomes were as follows: The interval between initiation of induction of labor and active phase of labor, length of different stages of labor, the interval between initiation of induction of labor and delivery and Bishop Score after induction. Two types of secondary outcomes were as follows: Maternal and neonatal outcomes. The maternal outcomes were Caesarean section rate, and adverse events. Neonatal outcomes included Apgar score at the 1st and 5th minutes after birth, fetal distress, meconium-stained liquid, and admission to neonatal intensive care unit (NICU).

\section{Study selection}

Following the initial search in the targeted databases, two of the authors ( $\mathrm{ZM}$ ) and ( $\mathrm{SH}$ F), independently screened titles and abstracts of the search results. Full text screening was conducted by the same two authors. Covidence was used for all screening, data extraction, and quality assessment. Any probable disagreement was resolved by discussion or asking assistance from the third author (E.K).

\section{Data extraction}

The authors used Covidence for data extraction and entered the data into Review Manager Software (RevMan 5.3). Details of the studies including the design of the study, inclusion and exclusion criteria, baseline characteristics, interventions, and outcomes were extracted by two of the authors (ZM and SH F), independently.

\section{Assessment risk of bias in included studies}

The risk of bias for each study was independently assessed by two reviewing authors (ZM and SH F) who 
used seven criteria suggested by Cochrane for the quality assessment of randomized controlled trials. These criteria included selection bias, performance bias, detection bias, attrition bias, selective reporting, and other risks of bias. If the authors had any discrepancy, they deliberated an issue to resolve it.

\section{Statistical analysis}

Different statistical procedures were taken for continuous and dichotomous data. Mean and standard deviation with $95 \%$ CIs were used for continuous data such as the interval between initiation of induction of labor and active phase of labor, the length of different stages of labor, Apgar score at the 1st and 5th minutes, and Bishop Score after induction. For dichotomous data, the results were presented as summary risk ratio or odds ratio (OR) with 95\% confidence intervals. Outcome measurement in all trials was similar. To demonstrate the effect size and $\mathrm{CI}$, Forest plots were used. Moreover, heterogeneity between the included studies was assessed by $\mathrm{I}^{2}$. By default, we used fixed effects for all pooled studies. If $\mathrm{I}^{2}>$ $50 \%$, the random effect model was used for the primary results of heterogeneity. Furthermore, sensitivity analyses were conducted to discover the potential source of heterogeneity if it was statistically significant across the studies. The authors performed sensitivity analyses by sequentially omitting one single study each time to test the robustness of uncertainty in the meta-analysis. Finally, all the data were analyzed using Review Manager (RevMan 5.3) statistical software from the Cochrane group. The significance level was set at 0.05 for random effects and fixed effects.

\section{Subgroup analysis and investigation of heterogeneity}

The following subgroup analyses were carried out: parenteral versus extra-amniotic administration of dexamethasone. Some outcomes were also used including the length of the interval between initiation of induction and delivery, mode of delivery, fetal distress, and admission to NICU.

\section{Results}

\section{Literature search}

Figure 1 Shows the flowchart of the selection process of studies. In our search of databases, 2672 articles were obtained as follows: Cochrane Library $(n=80)$, Scopus $(n=493)$, Web of Science $(n=178)$, PubMed $(n=1119)$, and EMBASE $(n=802)$. After removing duplicates $(n=$ 949) using Covidence, 1723 papers were screened of which, 26 eligible articles were selected for full-text screening, but we could not have access to the full-text of nine papers because these papers were published before 2000. Therefore, 17 articles were finally included in the study

\section{Characteristics and quality assessment of studies}

Out of the 17 studies included in this review, four investigated the effect of dexamethasone as an extra-amniotic infusion with a Foley catheter [18-21], and the rest assessed the effect of parenteral injection of dexamethasone on the duration of labor induction. We examined the outcomes of these two groups separately. Among these articles, eight studies were published in Egypt [12, 22-28], seven in Iran [7, 19, 20, 29-32], one in Iraq [18], and one in Israel [21]. All of them had an RCT design with fourteen using placebo and three having no intervention in their control groups. All of the studies assessed the effect of dexamethasone on nulliparous women except four studies that examined multiparous and nulliparous women [19-21, 29]. The range of women's age was between 18 and 35 years, and the gestational age was 37-42 weeks. All papers except one [23] used oxytocin for labor induction about 6 to $12 \mathrm{~h}$ after dexamethasone injection. Two papers did not mention their induction protocol $[19,30]$. The number of participants in studies differed from 31 to 86 in each group. The characteristics of the studies are demonstrated in Table 1.

Quality assessment of papers was conducted by two reviewers (ZM, SHF) according to Cochran Risk of Bias tool. The result of the assessment is presented in Fig. 2. The lowest biases were related selection bias, reporting bias, and attrition bias, respectively. However, most of the detection bias and allocation concealment signifies in the unclear risk. In terms of other types of bias, $50 \%$ of papers were in the low-risk zone and the others were in the high-risk zone.

\section{Overall meta-analysis}

The interval between induction of labor and active phase of labor

Ten articles including 1126 participants were analyzed in order to assess the effect of dexamethasone on the interval between the initiation of induction of labor and the active phase of labor. The result of the pooled analysis showed that the mean difference of this interval was shorter in the experimental group compared with the control group [MD: - 0.96, CI 95\% $(-1.06,-0.85)$; $P<0.00001]$. Because of high heterogeneity $\left(\mathrm{I}^{2}=74 \%\right.$; $P<0.0001)$, sensitivity analysis and random-effect analysis were done. By omitting one study [24], the heterogeneity reached $31 \%$. However, this interval was about 70 min shorter in the intervention group compared with the control group [MD: - 1.17, CI 95\% (-1.37, -1.00$)$; $P<0.00001]$.

In the subgroup of extra-amniotic administration of dexamethasone with Foley catheter, two papers reported this outcome. There were 163 participants. The analysis showed that the length of the interval between induction 


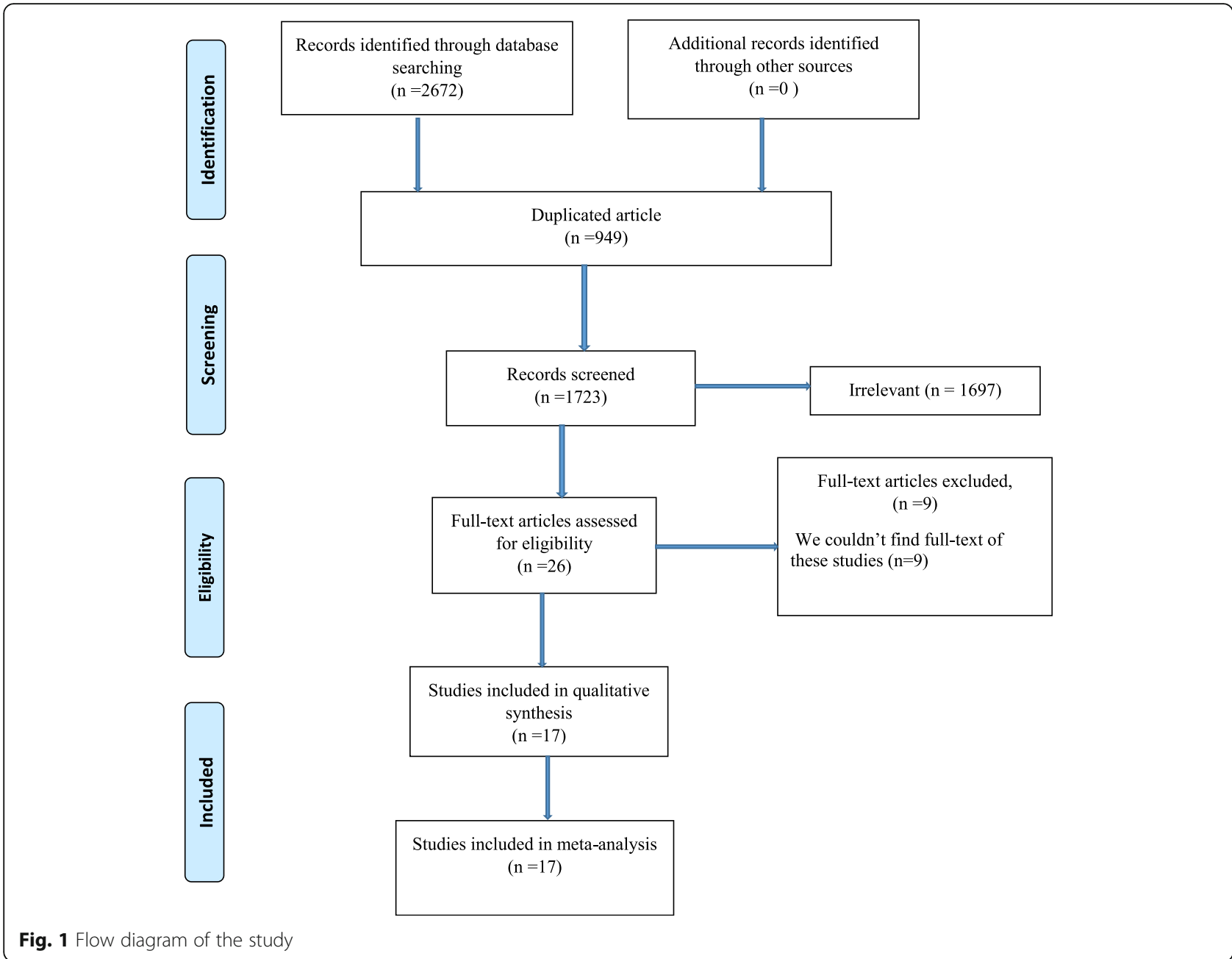

and active phase was $1 \mathrm{~h}$ and $49 \mathrm{~min}$ shorter in experimental group than that in the control [MD: - 1.83, CI 95\% (-2.79, -0.88$) ; P=0.0002]\left[\mathrm{I}^{2}=0 \% ; P=0.61\right]$. The results are displayed in Figs. 3 and 4.

\section{Length of the active phase of labor}

The pooled analysis of 10 papers including 1091 participants showed that the length of active phase is shorter in the experimental than in the control group [MD: 0.32 , CI 95\%(-0.41, -0.23$) ; P<0.00001]\left[\mathrm{I}^{2}=79 \%\right.$; $\mathrm{P}<$ $0.00001]$. After performing sensitivity analysis and eliminating the effect of two studies [7, 25], the heterogeneity reached 0\%. Random-effect analysis showed that the duration of the active phase was about 16 min shorter in the intervention than in the control group [MD: - 0.27, CI 95\% (-0.37, - 0.17); $P<0.00001]\left[\mathrm{I}^{2}=0 \% ; P<0.55\right]$. The forest plot of sensitivity analysis is presented in Fig. 5.

\section{Length of the first stage of labor}

Figure 6 exhibits the length of the first stage of labor in both intervention and control groups. The number of studies included is five and the number of participants in each group is 316 . The fixed-effect analysis showed the mean difference of the length of the first stage of labor in experimental group is shorter than that in the control [MD: - 0.96, CI 95\% $(-1.12,-0.80) ; P<0.00001]$ $\left[\mathrm{I}^{2}=97 \% ; P<0.00001\right]$. However, after removing 2 studies during sensitivity analysis $[23,26]$, the length of the first stage of labor in the dexamethasone group was nearly $88 \mathrm{~min}$ shorter than that in the control [MD: 1.47, CI 95\% $(-1.78,-1.16) ; P<0.00001]\left[\mathrm{I}^{2}=30 \% ; P=\right.$ $0.24]$.

\section{Length of the second stage of labor}

We assessed the length of the 2nd stage of labor in 10 articles involving 874 participants. The pooled analysis of these studies showed that the mean difference of the 


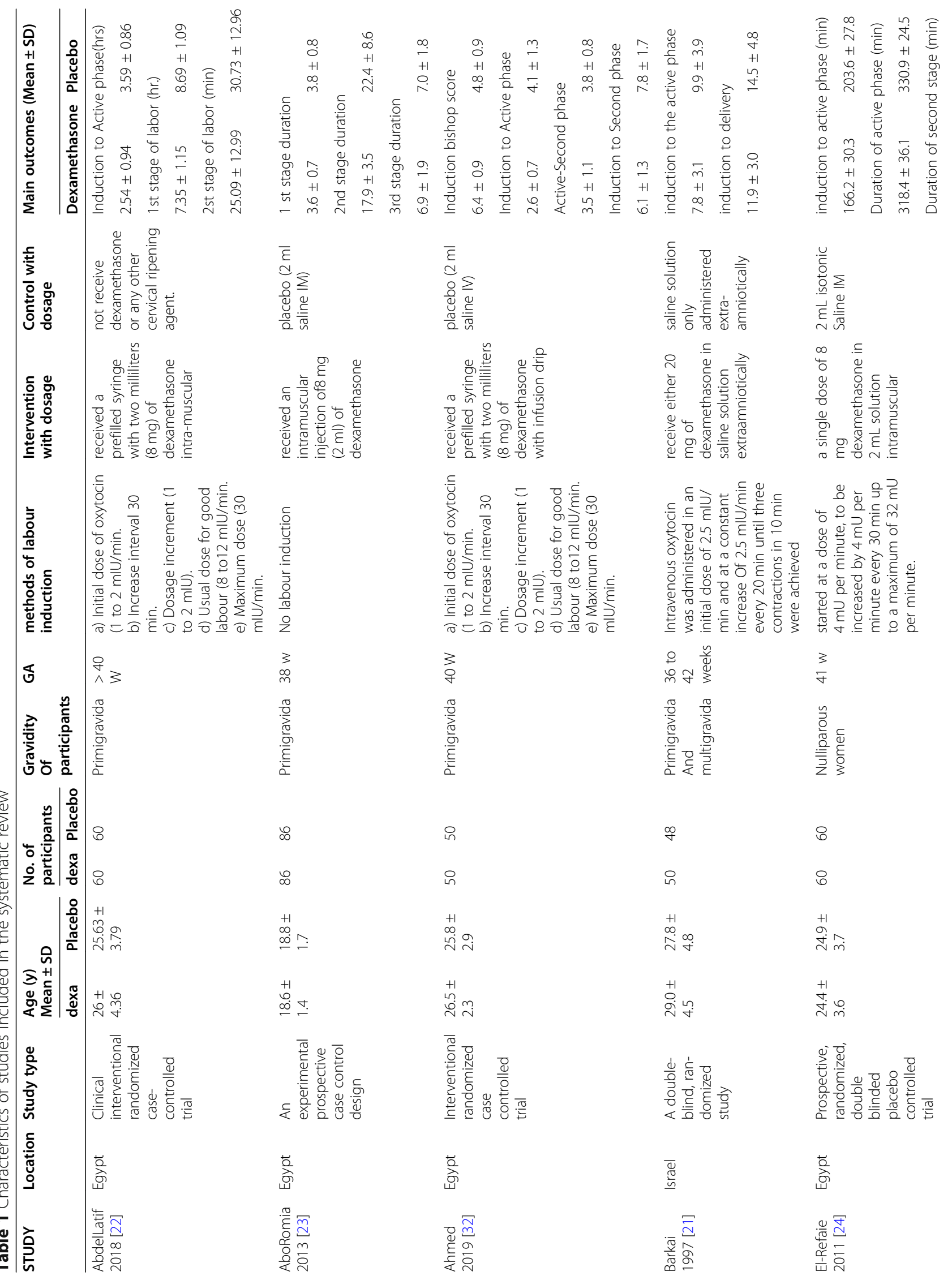




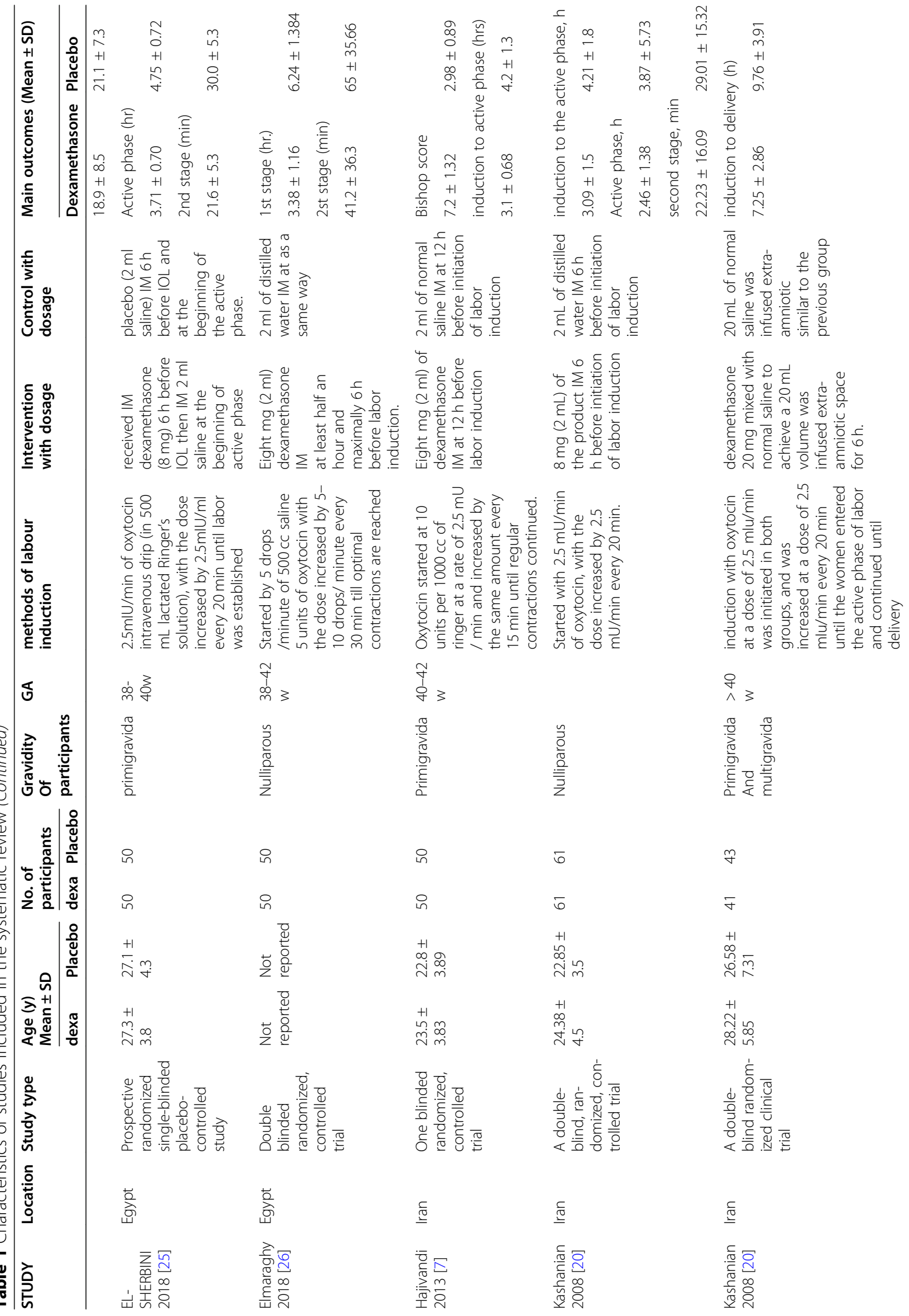




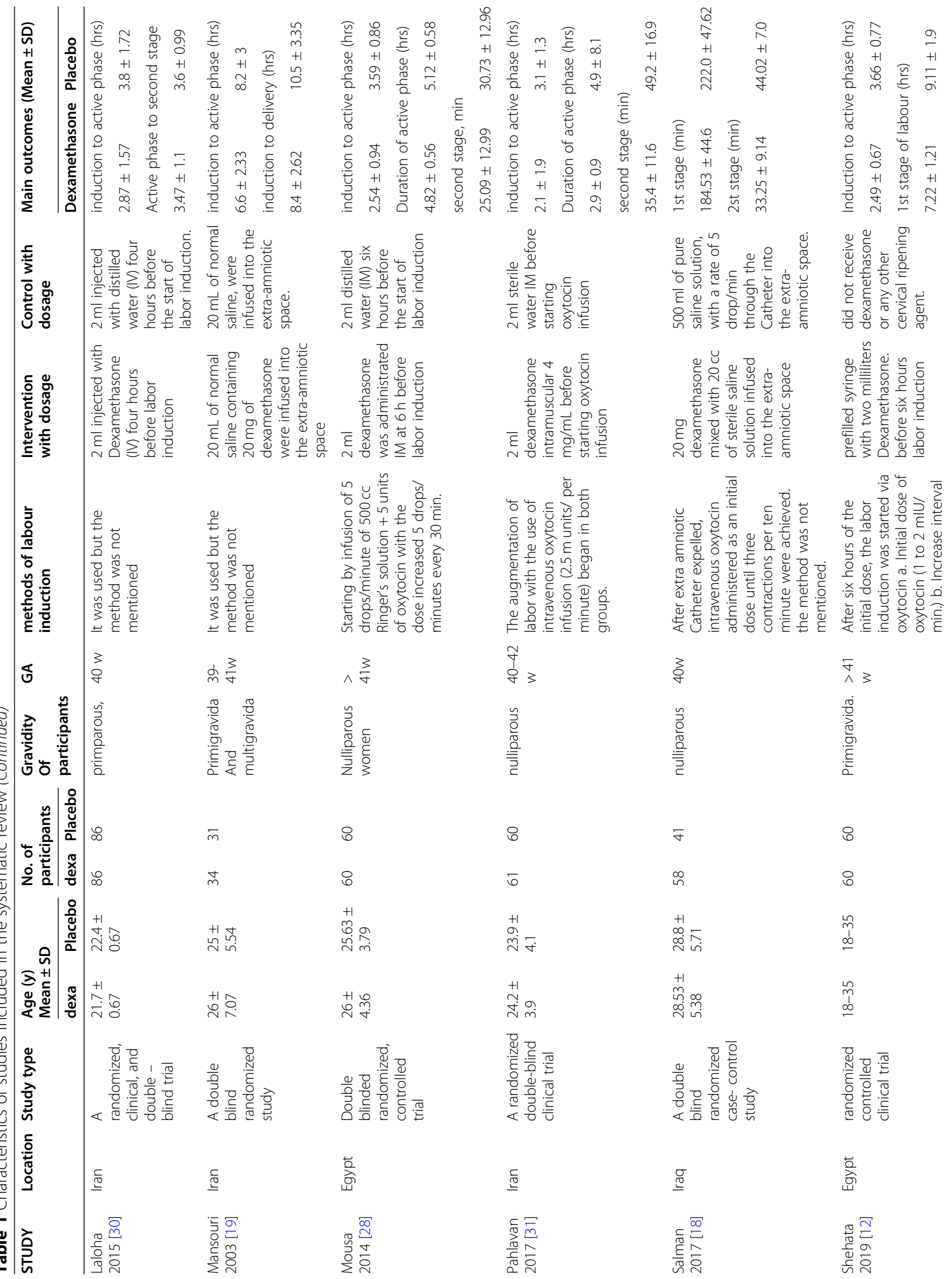




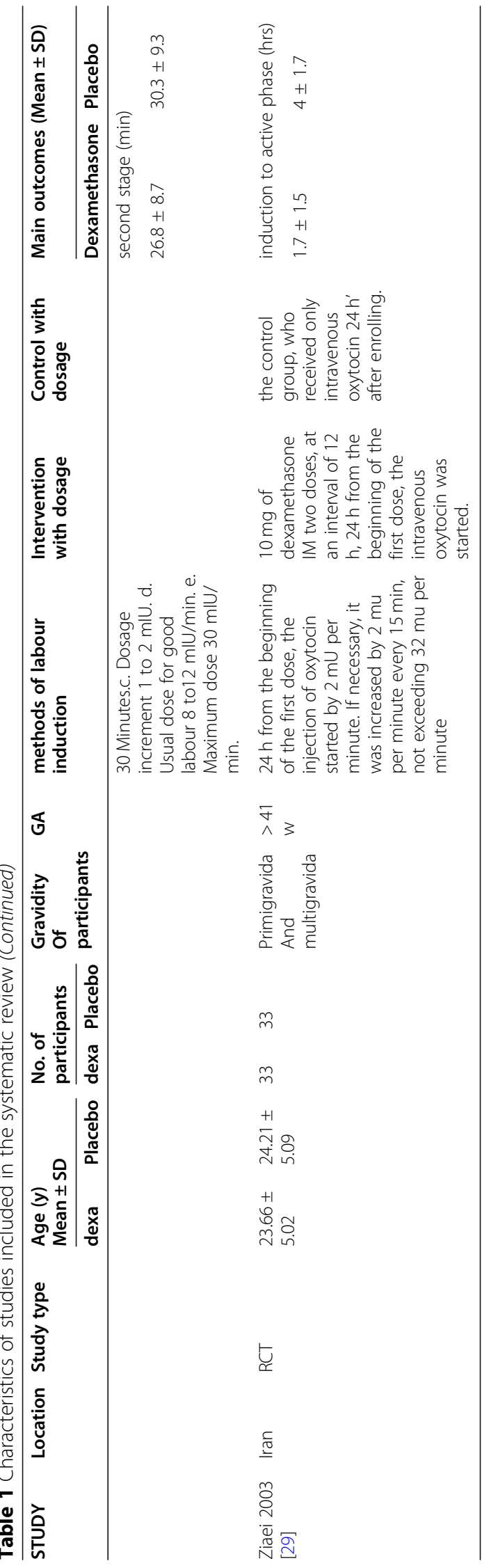




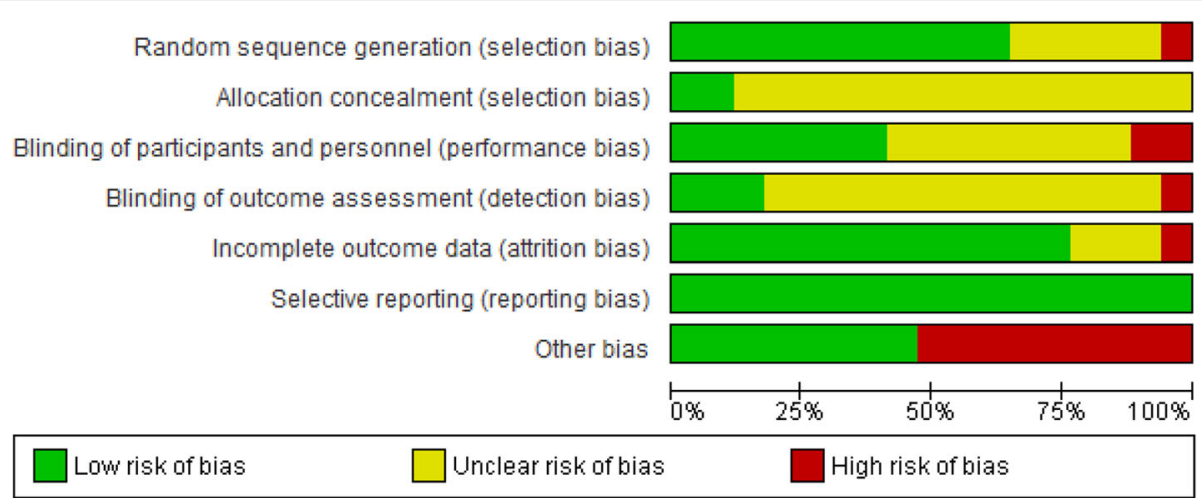

Fig. 2 'Risk of bias' summary: authors' judgments about each risk of bias item for included studies

second stage in experimental group is lower than that in the control group [MD: - 11.98, CI 95\% (-12.81, 11.15); $P<0.00001]\left[\mathrm{I}^{2}=98 \% ; P<0.00001\right]$. We conducted random-effect and sensitivity analysis to reduce heterogeneity. By omitting the effect of three articles $[25,26,31]$, heterogeneity reached $0 \%$, and the mean difference of the second stage in the experimental group was still lower than that in the control group [MD: - 4.21, CI 95\% (-5.43, - 2.99); $\mathrm{P}<$
0.00001]. That is, the second stage of labor was almost 4 min shorter in the experimental group (Fig. 7).

\section{Length of the third stage of labor}

The pooled analysis of nine papers with 1071 participants showed that although the length of the third stage in the experimental group was shorter than that in the control group based on the fixed-effect model [MD: 0.67, CI 95\% (-0.96, - 0.39); $\mathrm{P}<0.00001]\left[\mathrm{I}^{2}=98 \%\right.$; $\mathrm{P}<$

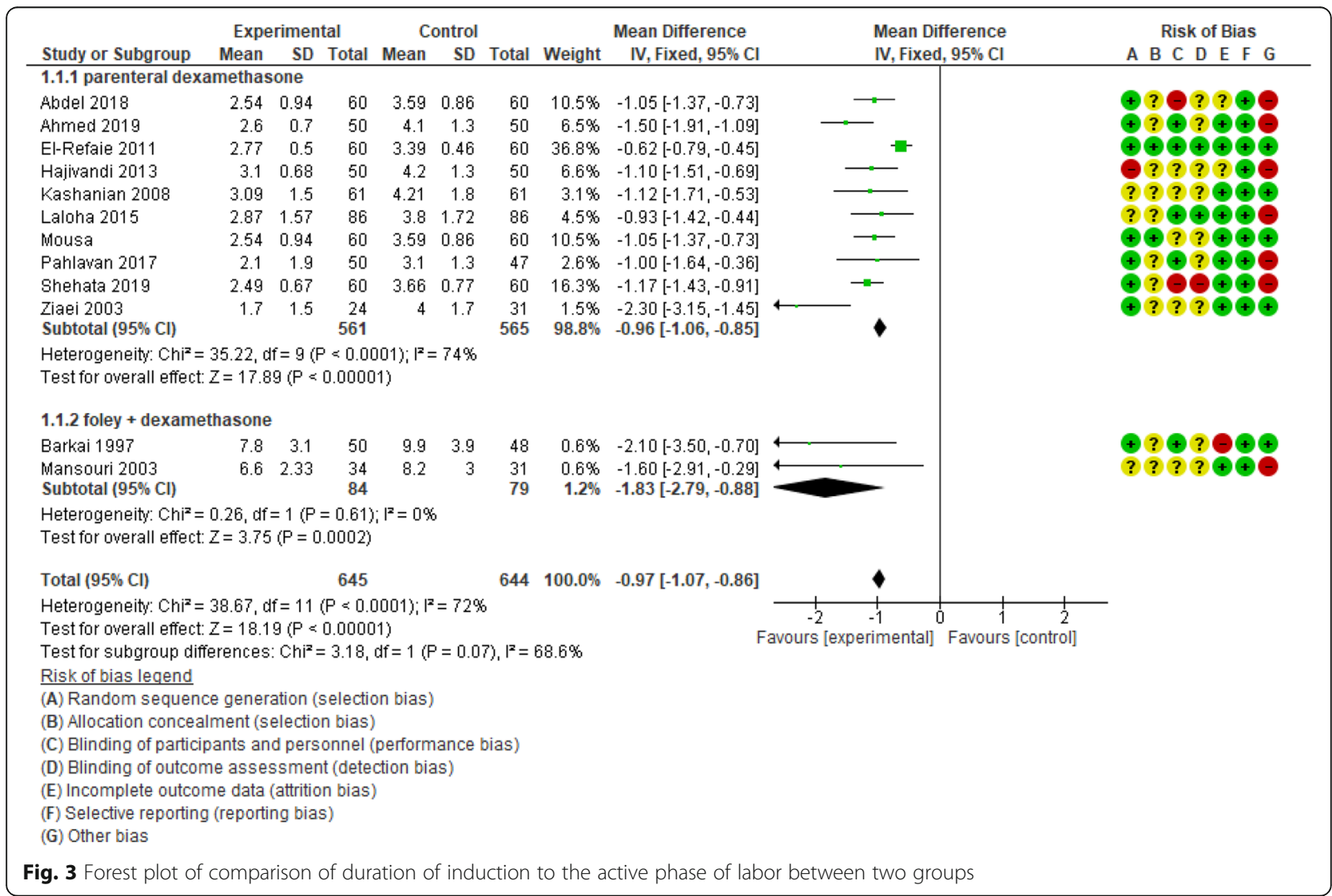




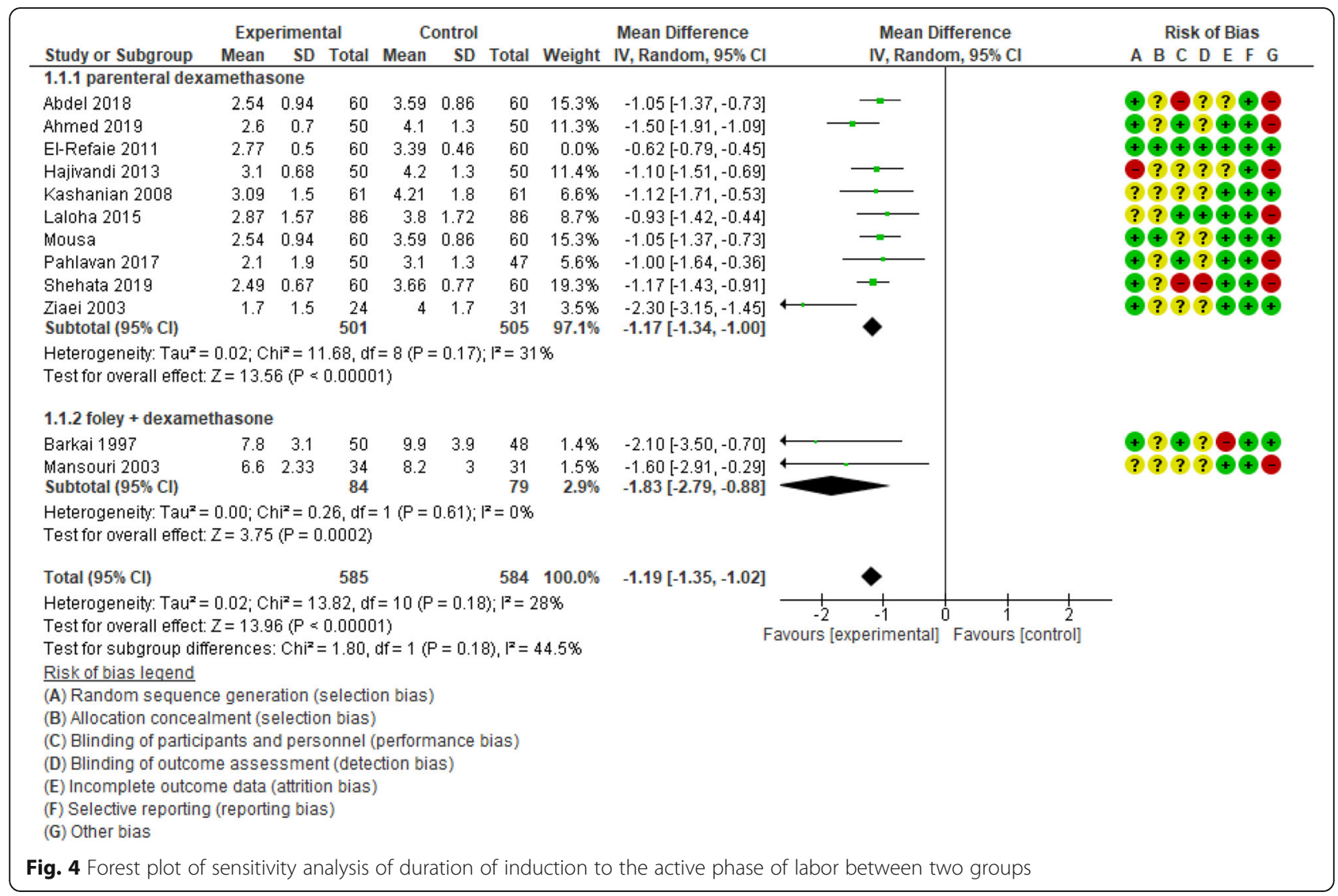

0.00001], after using the random-effect model and omitting the four studies [24-26,31], there was no difference between the groups [MD: -0.45 , CI $95 \%(-0.99,-0.1)$; $P<0.11]\left[\mathrm{I}^{2}=25 \% ; P=0.26\right]$.

\section{Mode of delivery}

This outcome was reported in two groups of induction of labor by parenteral dexamethasone and extra-amniotic injection of dexamethasone with a Foley catheter. Thus, we analyzed this outcome as a subgroup analysis.

\section{Normal vaginal delivery}

Figure 89 pt? $>$ shows the rate of NVD in the parenteral and extra-amniotic injection of dexamethasone with Foley catheter in the experimental and control groups. As shown in this figure, there are no differences between the two groups. The odds ratio of NVD in the parenteral dexamethasone subgroup in five studies was [1.51; CI 95\%(1.00, 2.28)], and that in the Foley subgroup in three studies was [0.99; CI 95\% $(0.51,1.94)]$.

\begin{tabular}{|c|c|c|c|c|c|c|c|c|c|c|c|}
\hline \multirow[b]{2}{*}{ Study or Subgroup } & \multicolumn{3}{|c|}{ Experimental } & \multicolumn{3}{|c|}{ Control } & \multirow[b]{2}{*}{ Weight } & \multirow{2}{*}{$\begin{array}{l}\text { Mean Difference } \\
\text { IV, Random, } 95 \% \mathrm{Cl}\end{array}$} & \multirow{2}{*}{\multicolumn{3}{|c|}{$\begin{array}{l}\text { Mean Difference } \\
\text { IV, Random, } 95 \% \mathrm{Cl}\end{array}$}} \\
\hline & Mean & SD & Total & Mean & SD & Total & & & & & \\
\hline Abdel 2018 & 4.82 & 0.56 & 60 & 5.12 & 0.58 & 60 & $23.9 \%$ & $-0.30[-0.50,-0.10]$ & $\rightarrow-$ & & \\
\hline Ahmed 2019 & 3.5 & 1.1 & 50 & 3.8 & 0.8 & 50 & $7.0 \%$ & $-0.30[-0.68,0.08]$ & & & \\
\hline El-Refaie 2011 & 5.3 & 0.6 & 60 & 5.51 & 0.4 & 60 & $29.9 \%$ & $-0.21[-0.39,-0.03]$ & -1 & & \\
\hline EL-SHERBINI 2018 & 3.71 & 0.7 & 50 & 4.75 & 0.72 & 50 & $0.0 \%$ & $-1.04[-1.32,-0.76]$ & & & \\
\hline Hajivandi 2013 & 3.56 & 1.5 & 50 & 3.18 & 0.47 & 50 & $0.0 \%$ & $0.38[-0.06,0.82]$ & & & \\
\hline Kashanian 2008 & 2.46 & 1.38 & 61 & 3.87 & 5.73 & 61 & $0.5 \%$ & $-1.41[-2.89,0.07]$ & & & \\
\hline Laloha 2015 & 3.47 & 1.1 & 86 & 3.6 & 0.99 & 86 & $10.2 \%$ & $-0.13[-0.44,0.18]$ & $\longrightarrow$ & - & \\
\hline Mousa & 4.82 & 0.56 & 60 & 5.12 & 0.58 & 60 & $23.9 \%$ & $-0.30[-0.50,-0.10]$ & $-\cdots$ & & \\
\hline Pahlavan 2017 & 2.9 & 0.9 & 50 & 4.9 & 8.1 & 47 & $0.2 \%$ & $-2.00[-4.33,0.33]$ & $\longleftarrow$ & & \\
\hline Shehata 2019 & 4.93 & 0.69 & 20 & 5.3 & 0.84 & 20 & $4.4 \%$ & $-0.37[-0.85,0.11]$ & & & \\
\hline Total $(95 \% \mathrm{Cl})$ & & & 447 & & & 444 & $100.0 \%$ & $-0.27[-0.37,-0.17]$ & $\varphi$ & & \\
\hline \multicolumn{9}{|c|}{$\begin{array}{l}\text { Heterogeneity: } \operatorname{Tau}^{2}=0.00 ; \mathrm{Chi}^{2}=5.94, \mathrm{df}=7(\mathrm{~F} \\
\text { Test for overall effect: } Z=5.24(\mathrm{P}<0.00001)\end{array}$} & $\begin{array}{ccc}-1 & 1 \\
\text { Favours [experimental] }\end{array}$ & $\begin{array}{cc}1 \\
0\end{array}$ & $\frac{1}{2}$ \\
\hline
\end{tabular}




\begin{tabular}{|c|c|c|c|c|c|c|c|c|c|c|}
\hline \multirow[b]{2}{*}{ Study or Subgroup } & \multicolumn{3}{|c|}{ Experimental } & \multicolumn{3}{|c|}{ Control } & \multirow[b]{2}{*}{ Weight } & \multirow{2}{*}{$\begin{array}{l}\text { Mean Difference } \\
\text { IV, Random, } 95 \% \mathrm{Cl}\end{array}$} & \multirow{2}{*}{\multicolumn{2}{|c|}{$\begin{array}{c}\text { Mean Difference } \\
\text { IV, Random, } 95 \% \mathrm{Cl}\end{array}$}} \\
\hline & Mean & SD & Total & Mean & SD & Total & & & & \\
\hline Abdel 2018 & 7.35 & 1.15 & 60 & 8.69 & 1.09 & 60 & $38.4 \%$ & $-1.34[-1.74,-0.94]$ & 二- & \\
\hline AboRomia 2013 & 3.6 & 0.7 & 86 & 3.8 & 0.8 & 86 & $0.0 \%$ & $-0.20[-0.42,0.02]$ & & \\
\hline Elmaraghy 2018 & 3.38 & 1.16 & 50 & 6.24 & 1.384 & 50 & $0.0 \%$ & $-2.86[-3.36,-2.36]$ & & \\
\hline Mousa & 7.35 & 1.15 & 60 & 8.69 & 1.09 & 60 & $38.4 \%$ & $-1.34[-1.74,-0.94]$ & 一— & \\
\hline Shehata 2019 & 7.22 & 1.21 & 60 & 9.11 & 1.9 & 60 & $23.1 \%$ & $-1.89[-2.46,-1.32]$ & 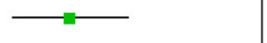 & \\
\hline Total $(95 \% \mathrm{Cl})$ & & & 180 & & & 180 & $100.0 \%$ & $-1.47[-1.78,-1.16]$ & & \\
\hline \multicolumn{7}{|c|}{$\begin{array}{l}\text { Heterogeneity: } \text { Tau }^{2}=0.02 ; \mathrm{Ch}^{2}=2.87, \mathrm{df}=2(\mathrm{P}=0.24) ; \mathrm{I}^{2}=30 \% \\
\text { Test for overall effect: } Z=9.31(\mathrm{P}=0.00001)\end{array}$} & & & $\begin{array}{ccc}-2 & -1 & 0 \\
\text { Favours [experimental] }\end{array}$ & $\begin{array}{l}1 \\
0 \\
\text { Favours [control] }\end{array}$ \\
\hline
\end{tabular}

\section{Cesarean section}

There were five papers including 580 participants in the parenteral dexamethasone. The odds ratio of $\mathrm{C} / \mathrm{S}$ in the experimental group was lower than that in the control group (OR: 0.61; CI 95\%: [0.40, 0.94]; $P=0.02$ ). Also, there were four papers with 330 participants in the extra-amniotic injection of dexamethasone. The odds ratio of $\mathrm{C} / \mathrm{S}$ did not differ between the two groups [OR: 0.93; CI 95\% (0.49, 1.76); $P=0.82$ ]. (See Fig. 9).

\section{Induction to delivery time interval}

This outcome was reported in one study using parenteral dexamethasone and three using Foley catheter. In both subgroups, there was a significant difference between the intervention and control groups in terms of the length of induction to delivery time interval. In the Foley subgroup, this interval in interventional group was $2 \mathrm{~h}$ and $23 \mathrm{~min}$ shorter than that in control group [MD: - 2.39, CI 95\%(-3.26, - 1.53); $P<0.00001]\left[\mathrm{I}^{2}=0 \% ; P=\right.$ 0.89 ]. In the parenteral subgroup, this interval in interventional group was $54 \mathrm{~min}$ shorter than that in control group [MD: - 1.90, CI 95\% (-2.40, - 1.40); $\mathrm{P}<0.00001$ ] (Fig. 10).

\section{Bishop score}

Four studies including 469 participants reported this outcome. The result of our analysis showed that there were significant difference between the intervention and control groups [MD: - 1.43, CI 95\% (-1.27, - 1.60); $\mathrm{P}<$ $0.00001]\left[\mathrm{I}^{2}=98 \% ; \mathrm{P}<0.00001\right]$. Random-effect analysis and sensitivity analysis were done because of high heterogeneity. By omitting two studies [7, 31], the mean difference of Bishop Score in the experimental group was almost 1.5 score smaller than that in the control group [MD: - 1.50, CI 95\% (-1.21, - 1.78); $\mathrm{P}<0.00001]\left[\mathrm{I}^{2}=\right.$ $0 \% ; P=0.33]$.

\section{Neonatal outcomes}

Fetal distress, Apgar score, meconium-stained liquid, and admission to the Neonatal Intensive Care Unit (NICU) were assessed in the included articles. None of the mentioned outcomes showed a statistically significant difference between the intervention and control groups in the subgroups of parenteral or extra-amniotic injection dexamethasone.

\section{Fetal distress}

We analyzed six papers which reported the rate of fetal distress. Four used parenteral administration [12, 22, 25, 28] including 230 participants in each group [OR: 0.75, CI 95\% (0.36, 1.58); $P=0.45]$, and two used extraamniotic injection $[19,21]$ with 147 participants [OR: 0.94 , CI $95 \%(0.18,4.80) ; P=0.94]$. There were no significant differences between groups.

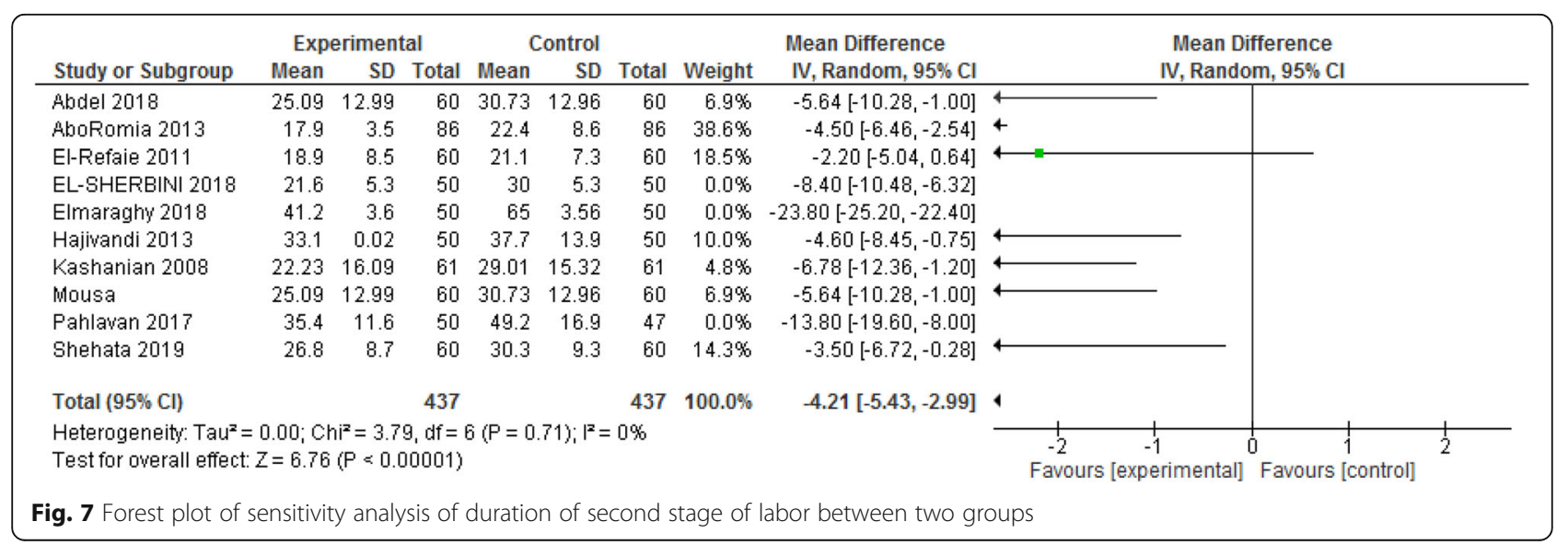




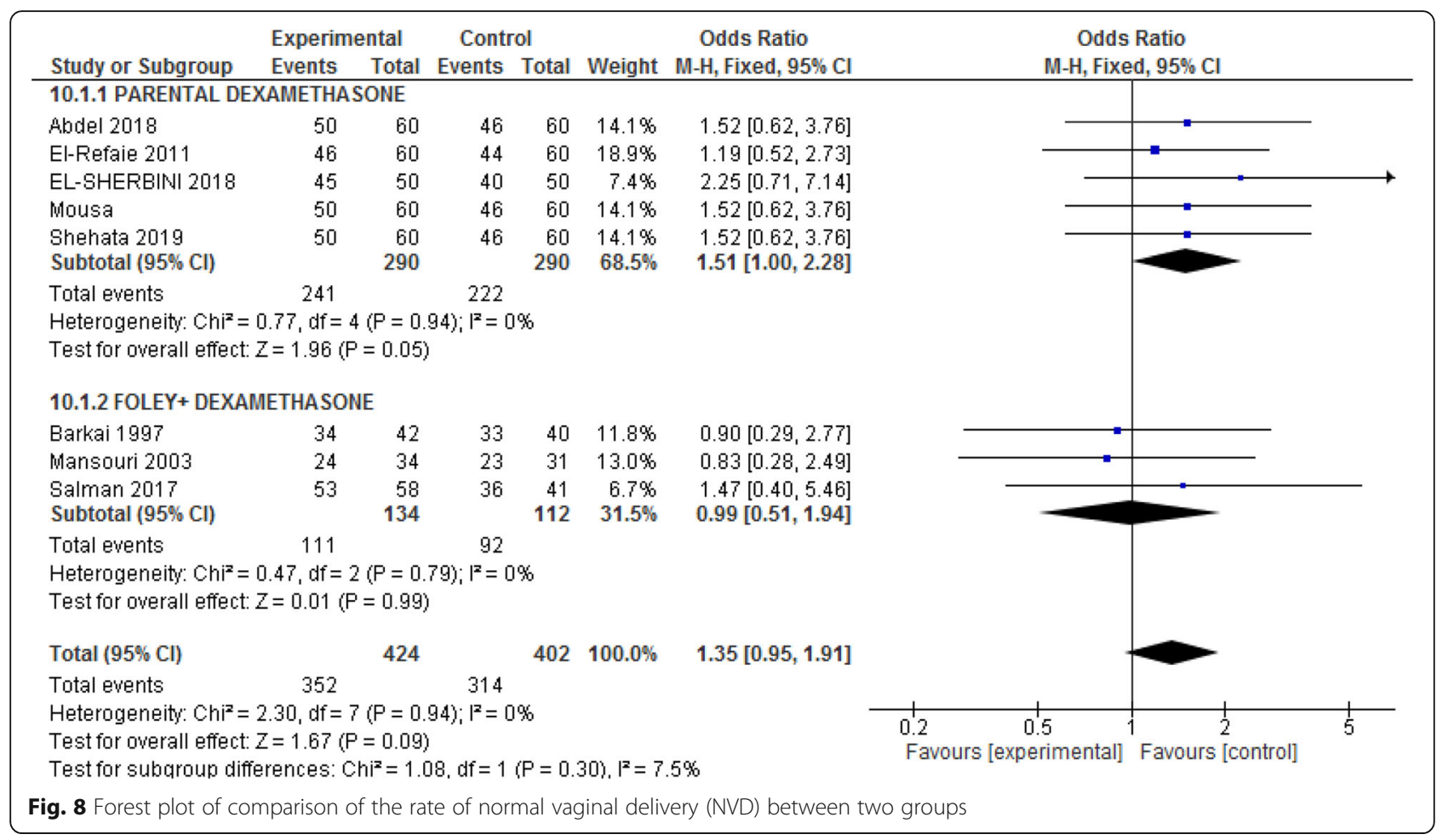

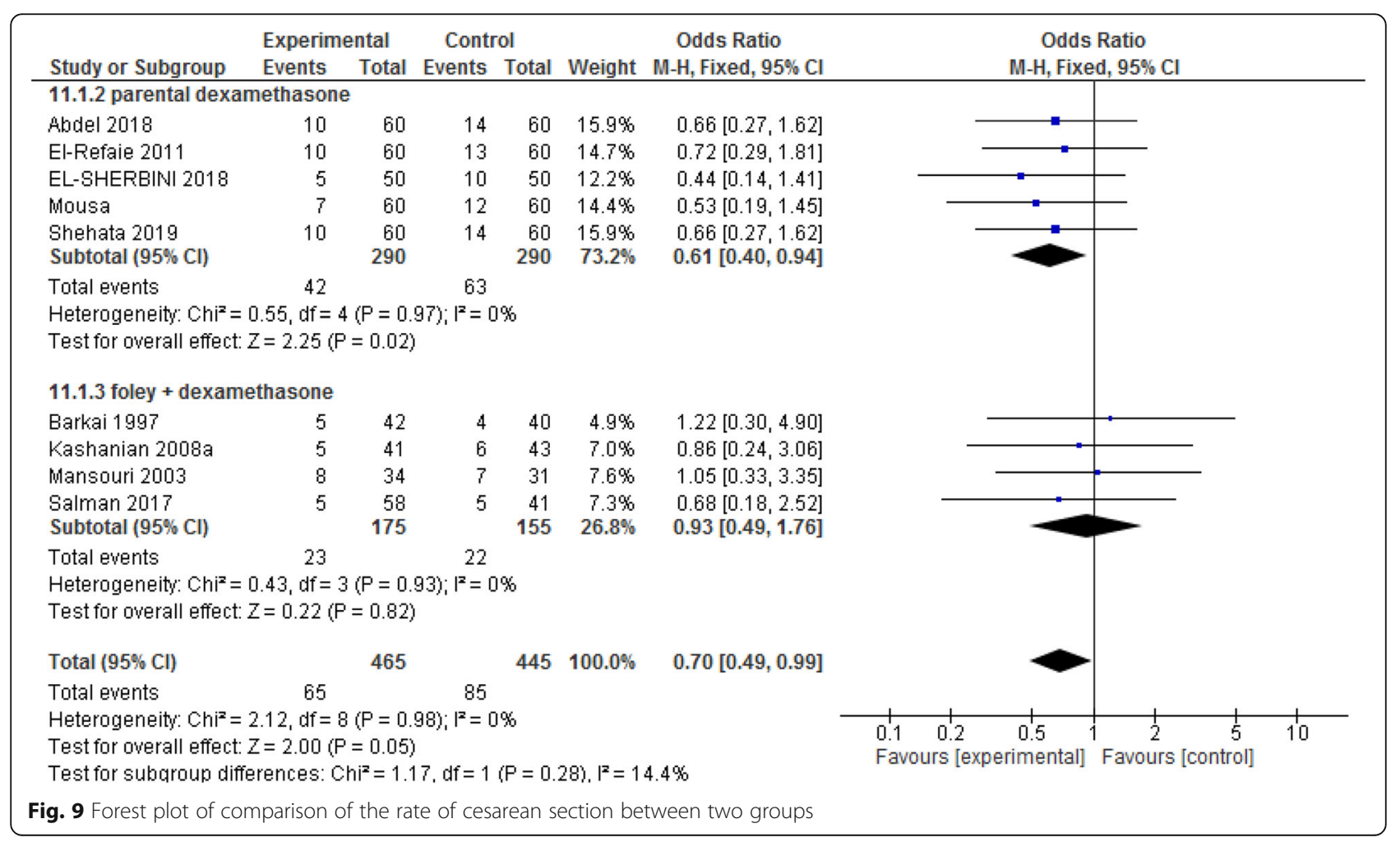




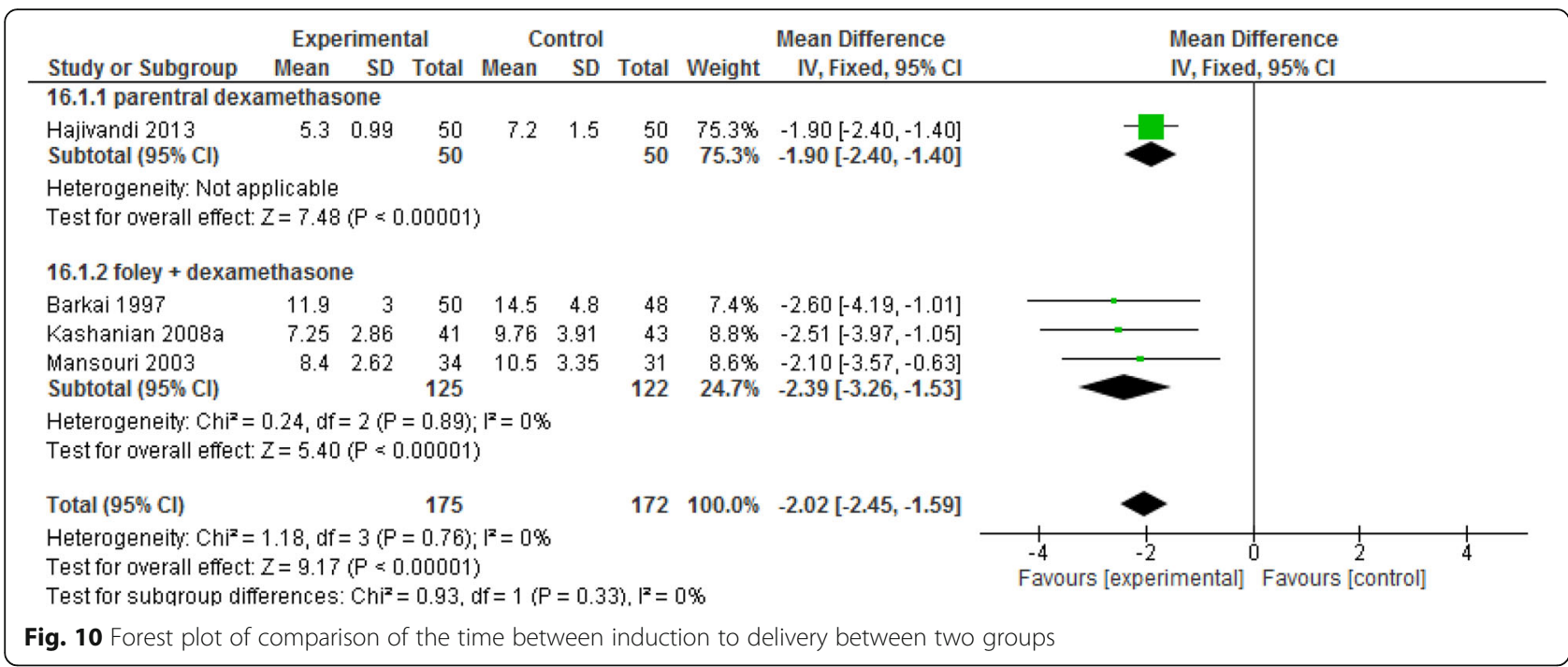

\section{Neonatal Apgar at the 1st minute}

Ten articles in the parenteral subgroup [7, 20, 22, 24, 25, 28, 30-33] reported the 1st minute Apgar score and involved 1091 participants. After sensitivity analysis and omitting one paper [7], there were no significant differences between the groups [MD: 0.08, CI 95\% (0.00, 0.16); $P=0.06$.

\section{Neonatal Apgar at the 5th minute}

Nine papers in the parenteral subgroup reported the 5 th minute Apgar score and involved 991 participants. There were no significant differences between groups [MD: 0.09 , CI 95\% (0.00, 0.18); $P=0.05]$.

\section{Admission to NICU}

Three papers in parenteral subgroup [12, 22, 32] and one in Foley subgroup [20] both with a total of 320 participants reported NICU admission. There were no significant differences between groups (OR: 0.71; CI 95\% $[0.31,1.62], P=0.4)$.

\section{Meconium-strained liquid}

This outcome was reported in three papers (two in parenteral subgroup [12, 22], and one in Foley subgroup [20]. Their total pooled analysis showed that there were no significant differences between the two groups (OR: 0.67; CI 95\% [0.24 1.87], $P=0.45)\left(\mathrm{I}^{2}=0 \%, P=0.91\right)$.

\section{Maternal outcomes}

Only three articles evaluated the mother's blood pressure (BP) as a maternal complication of parenteral injection of dexamethasone $[22,26,32]$. There were no significant differences between the intervention and control groups in terms of systolic BP [MD: -0.64, CI 95\% $(-2.76,1.47) ; P=0.55]$ and diastolic BP [MD: 0.89, CI 95\% (- 0.72, 2.49); $P=0.28$ ].

\section{Discussion}

This systematic review aimed to evaluate the effect of dexamethasone on labor induction. Our meta-analysis of 17 Randomized Controlled Trials (13 papers in the parenteral subgroup and four in the extra-amniotic injection subgroup) showed that the use of dexamethasone before the initiation of labor induction by any route of administration decreases the interval between induction and active phase, and the length of the first, second, and third stages of labor, and improves Bishop score after induction. We also found that dexamethasone injection does not affect maternal outcomes (caesarean section rate and blood pressure) or neonatal outcomes (Apgar score at 1st and 5th minute after birth, fetal distress, Meconium strained liquid, NICU admission).

Physiological processes regulating childbirth represent a series of biochemical changes in the uterus and cervix that result from endocrine and paracrine signals from the mother and fetus [1]. The role of Corticosteroids in the onset of labor is well unknown. Investigations on animals have shown that secretion of cortisol from the maturing fetal hypothalamus-pituitary-adrenal axis is important in initiating labor. According to these studies, after injection of a glucocorticosteroid, preterm labor was observed in lamb fetuses [33]. Glucocorticoids, especially cortisol, increase amniotic cyclooxygenase, increase prostaglandin synthesis, inhibit the activity of the chorionic prostaglandin dehydrogenase, and inhibit prostaglandin metabolism [34, 35]. Glucocorticoids are also strong stimulants in the production of placental $\mathrm{CRH}$. In the second half of pregnancy, CRH levels in the mother's bloodstream gradually increase and peak in the last six to 8 weeks before delivery. Women with high plasma $\mathrm{CRH}$ levels give birth earlier while those with lower $\mathrm{CRH}$ levels give birth later, indicating the impact 
of $\mathrm{CRH}$ production as an important factor in the onset of labor.

$\mathrm{CRH}$ does not have a direct inotropic effect on the human myometrium, but it does cause uterine vasodilation by affecting the placenta locally. It can also stimulate the secretion of dehydroepiandrosterone sulfate (DHEA-S) in fetal adrenal cortex cells. CRH enhances the effects of estrogen on these tissues of the uterus and cervix, increases prostaglandins in the amniotic sac, chorion, and decidua, and enhances the effect of oxytocin [35]. Several studies have reported that the injection of corticosteroids provokes successful induction of labor in lambs and humans. Since glucocorticoid receptors are present in the amniotic sac, glucocorticosteroids could carry out a possible role in parturition through paracrine or autocrine mechanisms [36].

Kalantaridou et al. (2007) reported that the corticotrophin-releasing hormone $(\mathrm{CRH})$ is the main corrector of the hypothalamic-pituitary-adrenal axis. Circulating placental $\mathrm{CRH}$ is responsible for the physiologic hypercortisolism of the second half of pregnancy and plays a role in the commencement of labor [15].

In humans, the production of $\mathrm{CRH}$ by the placenta and the increase of this hormone in maternal plasma are associated with the timing of parturition [37]. Recently, it has been shown that CRH stimulates the placenta for the production of estrogens and inhibits the production of progesterone [38]. Increasing the ratio of estrogen to progesterone in the mother's serum may progress the expression of contraction-associated proteins in the myometrium, thus facilitating the beginning of parturition [1, 39]. Furthermore, glucocorticoids induce the production of $\mathrm{CRH}$ by the placenta and the production of prostaglandins (PGF2 and PGE2) by fetal membranes [40].

\section{Limitations of this study}

Several limitations existed in this meta-analysis: 1) publication bias was not been measured; 2) Although most studies included in this review had examined the effect of dexamethasone on nulliparous women, some had not examined this effect on a parity basis.; 3) Most studies were conducted in Iran and Egypt, and the number of articles from other countries was small; 3) Maternal and neonatal outcomes had not been reported in all included studies completely. These limitations could have contributed to heterogeneity. On the other hand, given the possible effect of dexamethasone on neonatal outcomes [41, 42], none of the studies examined other outcomes such as neonatal hypoglycemia and the consequences of neurological and behavioral development in neonates born to these mothers.

\section{Conclusion}

Dexamethasone could significantly reduce the length of the time interval between induction and active phase and length of the first stage of labor with no difference in maternal or fetal adverse effects. Considering the high heterogeneity and quality of the studies included in this review, high-quality double-blind clinical trials are needed to be included in future reviews in order to draw more solid conclusion in this regard.

\section{Abbreviations}

RCT: Randomized controlled trial; CRH: Corticotrophin-releasing hormone; BMI: Body mass index; MD: Mean difference; OR: Odds ratio; Cl: Confidence Interval; AD: Anno Domini; NICU: Neonatal intensive care unit; NVD: Normal Vaginal Delivery; C/S: Cesarean Section; BP: Blood Pressure

\section{Supplementary Information}

The online version contains supplementary material available at https://doi. org/10.1186/s12884-021-04010-1.

\section{Additional file 1.}

\section{Acknowledgements}

Not applicable.

\section{Authors' contributions}

ZM, SHF were responsible for the design of the study. MZ was responsible for the searching process. ZM, SHF and EKL were involved in data screening and data extraction. ZM, SHF, HB and FSH wrote the manuscript. All authors read and approved the final version of the manuscript.

Funding

This study was not funded by any funding resource.

Availability of data and materials

Not Applicable.

\section{Declarations}

Ethics approval and consent to participate

Not Applicable.

Consent for publication

Not Applicable.

\section{Competing interests}

None.

\section{Author details \\ ${ }^{1}$ Family Health Department, Health Deputy, Tehran University of Medical Sciences, Tehran, Iran. ${ }^{2}$ Department of Midwifery, Marand Branch, Islamic Azad University, Marand, Iran. ${ }^{3}$ Department of Midwifery, Ahvaz Jundishapur University of Medical Sciences, Ahvaz, Iran. ${ }^{4}$ Department of Midwifery, School of Nursing and Midwifery, Kermanshah University of Medical Sciences, Kermanshah, Iran. ${ }^{5}$ Guilan Road Trauma Research Center, Biostatistics Department, Guilan University of Medical Sciences, Rasht, Iran. ${ }^{6}$ Liberian of Nursing and Midwifery School, Ahvaz Jundishapur University of Medical Science, Ahvaz, Iran.}

Received: 2 September 2020 Accepted: 19 July 2021

Published online: 17 August 2021

References

1. Cunningham FGGN, Leveno KJ, Gilstrap LC III, Hauth JC, Wenstrom KD. Williams obstetrics(23rd ed). New York: McGraw-Hill professional; 2018. ISBN: 978-0-07-170285-0 
2. WHO. WHO Recommendations for Induction of labour 2011. Available from: http://apps.who.int/iris/bitstream/10665/44531/1/9789241501156_eng.pdf. ISBN 9789241501156.

3. Centers for Disease Control and Prevention. Recent declines in induction of labor. 2014 march 1:http://www.cdc.gov/nchs/data/databriefs/db155.htm.

4. Asefa D, Ma G, Tolessa D, Abdulkadir Y. Induction of Labor Prevalence and Associated Factors for Its Outcome at Wolliso St. Luke, Catholic Hospital, South West Shewa, Oromia. Intern Med. 2017;7(5). Open Access. https://doi. org/10.4172/2165-8048.1000255.

5. Lueth GD, Kebede A, Medhanyie AA. Prevalence, outcomes and associated factors of labor induction among women delivered at public hospitals of MEKELLE town-(a hospital based cross sectional study). BMC Pregnancy Childbirth. 2020;20:1-10. https://doi.org/10.1186/s12884-02002862-7.

6. ACOG Practice Bulletin No. 107: Induction of labor. Obstet Gynecol. 2009; 114(2 Pt 1):386-97. https://doi.org/10.1097/AOG.0b013e3181b48ef5.

7. Hajivandi L, Montazeri S, Iravani M, Dawoodi M, Haghighizade MH. Effect of intramuscular dexamethasone on onset of labor in postdate pregnancy. J Babol Univ Med Sci. 2013;15:24-9 URL: https://www.researchgate.net/ publication/289020036_Effect_of_Intramuscular_Dexamethasone_on_ Onset_of_Labor_in_Postdate_Pregnancy.

8. Alfirevic Z, Keeney E, Dowswell T, Welton NJ, Medley N, Dias S, et al. Methods to induce labour: a systematic review, network meta-analysis and cost-effectiveness analysis. BJOG. 2016;123(9):1462-70. https://doi.org/1 0.1111/1471-0528.13981.

9. Alfirevic Z, Keeney E, Dowswell T, Welton NJ, Medley N, Dias S, et al. Which method is best for the induction of labour? A systematic review, network meta-analysis and cost-effectiveness analysis. Health Technol Assess. 2016; 20(65):1-583. https://doi.org/10.3310/hta20650

10. Grobman W, Lockwood CJ, Barss VA. Induction of labor with oxytocin. 2018. Uptodate; URL: https://www.uptodate.com/contents/induction-of-laborwith-oxytocin

11. Kawakita T, Reddy U, Huang C, Auguste T, Bauer D, Overcash R. Predicting vaginal delivery in nulliparous women undergoing induction of labor at term. Am J Perinatol. 2018;35(07):660-8. https://doi.org/10.1055/s-0037-1 608847

12. Shehata EE, Zaitoun MM, Azzam MN, Radwan ME. Effect of Intramuscular Administration of Dexamethasone on Labour Outcome in Induction of Primigravida at Late-Term Pregnancy. 2019;74(1):184-92. https://doi.org/1 0.21608/EJHM.2019.22649.

13. Campbell E, Linton E, Wolfe C, Scraggs P, Jones M, Lowry P. Plasma corticotropin-releasing hormone concentrations during pregnancy and parturition. J Clin Endocrinol Metab. 1987;64(5):1054-9. https://doi.org/1 0.1210/jcem-64-5-1054.

14. Meyer E, Nenke M, Rankin W, Lewis J, Torpy DJ. Corticosteroid-binding globulin: a review of basic and clinical advances. Horm Metab Res. 2016 48(06):359-71. https://doi.org/10.1055/s-0042-108071.

15. Kalantaridou S, Makrigiannakis A, Zoumakis E, Chrousos GP. Peripheral corticotropin-releasing hormone is produced in the immune and reproductive systems: actions, potential roles and clinical implications. Front Biosci. 2007;12(1):572-80. https://doi.org/10.2741/2083.

16. Stjernholm TV, Nyberg A, Cardell M, Höybye C. Circulating maternal cortisol levels during vaginal delivery and elective cesarean section. Arch Gynecol Obstet. 2016;294(2):267-71. https://doi.org/10.1007/s00404015-3981-x.

17. Yao X, Florez ID, Zhang P, Zhang C, Zhang Y, Wang C, et al. Clinical research methods for treatment, diagnosis, prognosis, etiology, screening, and prevention: A narrative review. J Evid-Based Med. 2020;13(2):130-6. https:// doi.org/10.1111/jebm.12384.

18. Salman ST. Cervical ripening by using extra-amniotic dexamethasone infusion versus extra-amniotic saline infusion. J Facult Med. 2017;59(4):299_ 02. https://doi.org/10.32007/jfacmedbagdad.59468.

19. Mansouri M, Pourjavad A, Panahi G. Induction of labor with use of a Foley catheter and extraamniotic corticosteroids. Med J Islam Repub Iran. 2003; 17(2):97-100.

20. Kashanian M, Fekrat M, Naghghash S, Ansari NS. Evaluation of the effect of extra-amniotic normal saline infusion alone or in combination with dexamethasone for the induction of labor. J Obstet Gynaecol Res. 2008; 34(1):47-50. https://doi.org/10.1111/j.1447-0756.2007.00703.x.

21. Barkai G, Cohen SB, Kees S, Lusky A, Margalit V, Mashiach S, et al. Induction of labor with use of a Foley catheter and extraamniotic corticosteroids. Am
J Obstet Gynecol. 1997;177(5):1145-8. https://doi.org/10.1016/s0002-93 78(97)70031-0.

22. Abdel Latif EM, Taha WS, Ahmed AARA. Effect of Intra-Muscular Administration of Dexamethasone on the Duration of Induction of Labor in Primigravida Full-Term Pregnancy. Egyptian J Hosp Med. 2018;73(6):6973-82. https://doi.org/10.21608/EJHM.2018.17213.

23. AboRomia F, El-Adham AF. Influence of intramuscular dexamethasone on labor duration in primigravidas. Tanta Sci Nurs J. 2013:4(1):143-54. https:// doi.org/10.21608/tsnj.2013.74465.

24. El-Refaie T, Yehia M, Younan R. Effect of dexamethasone on the duration of labor among women undergoing labor induction: a randomized controlled trial. J Egypt Soc Gynaecol Obstet. 2011;37(1):595-9.

25. El-Sherbini M, Helal O, Zaki MD, Sherif $\mathrm{S}$. The effect of intramuscular Administration of Dexamethasone Alone or in combination with hyoscine Butylbromide in shortening the duration of induced labor in Primigravidas. Med J Cairo Univ. 2018;86(September):2335-40. https://doi.org/10.21608/ mjcu.2018.57534.

26. Elmaraghy MA-A, El Refaie T, Labib KM, Mohamed MG. Effect of intramuscular administration of dexamethasone on the duration of labor induction. Evid Based Womens Health J. 2018;8(4):311-7. en. https://doi. org/10.21608/EBWHJ.2018.20075

27. Ahmad A, Webb SS, Early B, Sitch A, Khan K, MacArthur C. Association between fetal position at onset of labor and mode of delivery: a prospective cohort study. Ultrasound Obstet Gynecol. 2014;43(2):176-82. https://doi.org/10.1002/uog.13189.

28. Mousa K, Awadalla A, Ezat T. Effect of Intramuscular Administration of Dexamethasone on the Duration of Labor in Postterm Induced Delivery. Ain Shams Med J. 2014;65(1,2\&3). https://doi.org/10.12816/001342.

29. Ziaei S, Rosebehani N, Kazeminejad A, Zafarghandi S. The effects of intramuscular administration of corticosteroids on the induction of parturition. J Perinat Med. 2003;31(2):134-9. https://doi.org/10.1515/JPM.2 003.018.

30. Fatemeh L, Negin A, Ameneh B, Farideh M, Ezzatossadat Haj Seyed J. Effect of Intravenous Dexamethasone on Preparing the Cervix and Labor Induction. Acta Medica Iranica. 2015;53(9):568-72.

31. Pahlavan Z, Barat S, Esmaeilzadeh S, Ghanbarpour A, Naeimirad M, Golsorkhtabaramiri M. The effect of dexamethasone therapy on prolonged latent phase of labor: a randomized double-blind clinical trial. Caspian J Reprod Med. 2017;3(1):33-8 URL: http://caspjrm.ir/article-1-117-en.html.

32. Ahmed AEM, Deif OM, El-Saftawy MA. Potency of Dexamethasone in Labor Induction. Egypt J Hosp Med. 2019;74(7):1544-51. en. https://doi.org/10.21 608/EJHM.2019.27861.

33. Kavanagh J, Kelly AJ, Thomas J. Corticosteroids for cervical ripening and induction of labour. Cochrane Database Syst Rev. 2006;(2):CD003100. https://doi.org/10.1002/14651858.CD003100.pub2.

34. Petraglia F, Benedetto C, Florio P, D'Ambrogio G, Genazzani AD, Marozio L, et al. Effect of corticotropin-releasing factor-binding protein on prostaglandin release from cultured maternal decidua and on contractile activity of human myometrium in vitro. J Clin Endocrinol Metab. 1995; 80(10):3073-6. https://doi.org/10.1210/jcem.80.10.7559899.

35. Errol R Norwitz, Charles J Lockwood, Vanessa A Barss. Physiology of parturition at term [Internet]. 2021. UpToDate. Available from: https://www2. utdos.ir/contents/physiology-of-parturition-at term?search= Physiology\%20of\%20parturition\%20at\%20term\&source=search_. result\&selectedTitle $=1 \sim 150 \&$ usage_type=default\&display_rank=1.

36. Pushpalatha K. A Comparative Study of Extra-Amniotic Infusion of Corticosteroids versus Normal Saline for Induction of Labour. Internet J Third World Med. 2008:8(1).

37. McLean M, Bisits A, Davies J, Woods R, Lowry P, Smith R. A placental clock controlling the length of human pregnancy. Nat Med. 1995;1(5):460-3. https://doi.org/10.1038/nm0595-460.

38. Yang R, You X, Tang X, Gao L, Ni X. Corticotropin-releasing hormone inhibits progesterone production in cultured human placental trophoblasts. J Mol Endocrinol. 2006;37(3):533-40. https://doi.org/10.1677/jme.1.02119.

39. Mastorakos G, Ilias I. Maternal and fetal hypothalamic-pituitary-adrenal axes during pregnancy and postpartum. Ann N Y Acad Sci. 2003;997(1):136-49. https://doi.org/10.1196/annals.1290.016.

40. Cheng YH, Nicholson RC, King B, Chan EC, Fitter JT, Smith R. Corticotropinreleasing hormone gene expression in primary placental cells is modulated by cyclic adenosine 3',5'-monophosphate. J Clin Endocrinol Metab. 2000;85(3): 1239-44. PubMed PMID: 10720069. https://doi.org/10.1210/jcem.85.3.6420. 
41. Zipori Y, Zidan R, Lauterbach R, Hagag A, Ginsberg Y, Solt I, et al. Antenatal betamethasone and the risk of neonatal hypoglycemia: it's all about timing. Arch Gynecol Obstet. 2021;303(3):695-701. https://doi.org/10.1007/s00404020-05785-y.

42. Franks, AL, Berry, K, DeFranco, DB. Prenatal drug exposure and neurodevelopmental programming of glucocorticoid signalling. J Neuroendocrinol. 2020; 32:e12786. https://doi.org/10.1111/jne.12786.

\section{Publisher's Note}

Springer Nature remains neutral with regard to jurisdictional claims in published maps and institutional affiliations.

Ready to submit your research? Choose BMC and benefit from:

- fast, convenient online submission

- thorough peer review by experienced researchers in your field

- rapid publication on acceptance

- support for research data, including large and complex data types

- gold Open Access which fosters wider collaboration and increased citations

- maximum visibility for your research: over $100 \mathrm{M}$ website views per year

At BMC, research is always in progress.

Learn more biomedcentral.com/submissions 